\title{
Mountain Bike Tourism Economic Impacts: A Critical Analysis of Academic and Practitioner Studies
}

\begin{abstract}
Mountain biking as a sport and recreational activity has grown rapidly over the previous two decades. Consequently, there has been growth recently in efforts aimed at stimulating mountain bike tourism through the development and marketing of mountain bike trails and parks. Various community advocates, academics, and industry practitioners have sought to quantify the economic impacts of mountain bike tourism in order to garner public and other financial assistance to aid development of mountain bike tourism. This research critically reviewed 33 academic and practitioner studies reporting on mountain bike tourism economic impacts. Analysis revealed widespread inconsistency in instrumentation and variable measurement contributing to a fragmented body of knowledge pertaining to economic impacts of mountain bike tourism. Recommendations for improved rigor and consistency in future research measuring mountain bike tourism impacts are provided.
\end{abstract}

Keywords: Mountain biking; tourism impacts; tourism policy; economic impact; visitor spending; cycling tourism 


\section{Introduction}

Mountain biking has evolved from humble beginnings in the 1980s into a global sport and recreational activity (Kelly, 2014). Amateur cyclists now travel extensively to experience destinations known for iconic trail offerings such as Whistler in Canada, and Derby in Tasmania, Australia (Courtney, 2018). Tourism strategies based around cycling tourism are frequently utilized as economic diversification and/or revitalization strategies in western countries, particularly in non-urban communities featuring desirable geographic terrain (Reis, Lovelock, and Jellum, 2014). Relatedly, investment in the development of trail systems and related resources to leverage rising popularity of mountain biking is growing in such destinations (Freeman and Thomlinson, 2014). Mountain bike tourism strategies are typically focused on attracting visitors through hosting events and promoting general visitation to ride a variety of trail networks and/or specialized mountain bike parks (Moularde and Weaver, 2016).

Governments and to a lesser extent, private sector organizations in countries such as the United States, Australia, the United Kingdom, and New Zealand, offer grant schemes for community development projects likely to deliver economic, social, and/or health benefits (e.g., Jenkins, 2000; Moscardo, 2005). Applicants must compile and justify a convincing business case in order to attain such funding (Hodur and Leistritz, 2006). However, cycling tourism initiatives such as rail trail developments and mountain bike parks are commonly driven through a grassroots bottom-up approach, with networks of individuals and organizations pooling their skills and resources to champion such initiatives (Beeton, 2010). As we shall argue in this research note, community groups seeking to develop a business case for mountain bike tourism development funding are currently hampered by an incoherent body of empirical knowledge to effectively articulate the size and economic worth of the mountain bike tourism market. 
Weed (2005) advocated that researchers should strive to construct 'edifices' of knowledge (p. 78) that, through research synthesis, facilitate broader, more accurate understandings of economic impacts attributable to sport and tourism phenomena. However, doing so requires explicit attention being paid to existing literature, and adherence to accepted methodological protocols for producing valid economic impact estimates (Hudson, 2001). Indeed, numerous authors have published critiques of economic impact studies within the related fields of tourism and sport management, pointing out the widespread violation of economic impact methodological protocols (e.g., Crompton, 1995; Hodur and Leistritz, 2006; Hudson, 2001).

As we shall demonstrate, improved understanding and synthesis of published research on mountain bike tourism impacts is needed to better enable communities to acquire resources, secure funding, navigate legislation, and gain stakeholder support to develop mountain bike tourism (Buning, Cole, and Lamont, 2019; Freeman and Thomlinson, 2014). Therefore, our aim in this research note is to critique existing academic and practitioner literature with regard to measurement of mountain bike tourism economic impacts. By doing so, we seek to make a range of recommendations for facilitating a more coherent, comparable, and compelling evidence base to convey the scope and contributions of the mountain bike tourism segment globally, and to aid communities in developing mountain bike tourism.

\section{Method}

This study reviewed published English language academic and practitioner literature addressing mountain bike tourism impacts. Using the process described in Moher et al.'s (2009) PRISMA statement, records were identified, screened, and then assessed for eligibility in the review. Keyword searches were performed within several online databases to identify 
relevant sources which primarily included Google, Google Scholar, University Libraries, and Academic Search Premier. Online repositories of related reports assisted in the search process including the Headwaters Economics Trail Benefits Library (headwaterseconomics.org/trail/) and the International Mountain Bike Association (IMBA) Resource Hub (imba.com/explore$\mathrm{imba} /$ resource-hub). Citation lists within identified documents were also examined to identify additional relevant material. Search terms included variations of the main search term 'mountain biking' (e.g., mountain bike, mountain cycle, off-road cycling), combined with other relevant keywords including variations of 'economic impact', 'visitor impact', 'tourism impact', and 'economy'. The tags 'pdf' and 'ppt' were also included as they directly returned several relevant practitioner reports. The search process returned a variety of academic journal articles, industry reports, government briefs, popular press articles, and presentation files.

Initially, document titles and/or abstracts were assessed for relevance, which returned 89 studies. The following criterion were used to qualify the documents for inclusion in the review:

- Documents returned from the search process which addressed cycling generally, and/or did not differentiate mountain biking from other forms of cycling, or were not specifically focused on tourism were excluded.

- Studies that did not directly report visitor spending from the study being reported were excluded.

- Studies that were deemed to not fit the definition of mountain bike tourism proposed by Moularde and Weaver (2016) as 'trips of at least 24 hours away from a person's home environment for which active participation in mountain biking for recreational purposes is the primary motivation and determining factor in destination choice' (p. 3) were excluded. 
- Documents that did not report empirical research findings such as popular press articles and other web-based documents (e.g., forum posts) were excluded.

- Duplicate reports of the same datasets such as summary documents were also excluded.

Consequently, 33 studies were included in the review and subjected to exploratory analysis to identify the range of mountain bike tourism impact variables measured in those studies along with variable measurement characteristics. The 33 studies were published in 21 industry reports, 2 government briefs, 4 academic journal articles, and 4 academic reports were included. The data was collected primarily in the United States (16), Canada (13), United Kingdom (1), New Zealand (1) and South Africa (1). The studies were focused around assessing visitor expenditure around events (11), trail systems (8), park/conservation areas (5), municipalities (3), regions (4), and state (1). The earliest studies discovered were published in 1997 and the latest in 2018.

A database was then created to record and summarize the results of each study with a focus on capturing the range of variables measured, along with intra-variable measures. Categories developed in the database included: author(s); year of publication; title, type of study; sample size; respondents' demographics; individual mountain biking characteristics; destination choice variables; mountain bike tourism travel characteristics; and mountain bike tourism expenditure.

\section{Findings}

In total, 26 variables were measured across the 33 studies (Table 1). The most prevalent variables measured were total expenditure during a mountain biking trip (90.9\%), respondents' age (69.7\%), expenditure on lodging (66.7\%), and gender $(66.7 \%)$. The least prevalent variables were types of mountain biking (3.0\%) and time spent mountain biking 
each day (3.0\%). The largest number of variables measured within a study was 17 (Western Canada Mountain Bike Tourism Association, 2017), whilst one study only reported a single variable, total expenditure during a mountain bike trip (Tabor, 2014).

\section{Insert Table 1 here}

Most notably, our analysis revealed considerable inconsistency in the range of variables measured across the studies, particularly economic impact measures. For example, some studies measured visitor expenditure across multiple categories encompassing lodging, food and beverage, shopping, recreation, and/or rental vehicles to calculate total spending estimates (e.g., Destination British Columbia, 2013; Dean Runyan Associates, 2013; Western Canada Mountain Bike Tourism Association, 2006). In contrast, another study (Boozer and Self, 2012) only measured expenditure data on a per-day basis for two generic expenditure categories (lodging and non-lodging). Other studies measured a combination of total daily expenditure and total daily expenditure per person (e.g., Fix and Loomis, 1997), while others simply measured aggregate expenditure per trip (e.g., Chakraborty and Keith, 2000; Preez and Lee, 2016; Tabor, 2014). As will be elaborated upon later, this inconsistent approach to instrumentation intended to measure mountain bike tourism economic impacts is problematic.

Our analysis also identified inconsistency relating to the measurement and reporting of individual variables, particularly categorical variables intended to measure respondents' demographic and mountain bike participation characteristics. There was also inconsistent use of categorical and continuous measures, along with considerable diversity in category responses offered; these conditions prevented a meta-analysis of the studies from being undertaken, as 'meta-analysis should only be used when studies are similar in terms of their population, address the same substantive issue, and use the same statistical procedure and 
manipulations' (Weed, 2005, p. 80). For example, mountain biking skill level was a variable measured in $8(24.2 \%)$ of the studies; one of those studies (an academic consultant report, Sumathi and Berard, 1997) measured skill utilizing a binary variable of novice/advanced, whereas an academic study of mountain bike tourism economic impacts (Moran, Tresidder, and McVittie, 2006) measured skill utilizing a four-point scale (beginner, intermediate, advanced, and expert). This is but one example of how comparisons between various studies on variables where divergent measures have been used, are compromised within this body of literature.

Insert Table 2 Here

\section{Conclusions and Recommendations}

Although our review identified a paucity of comparable estimates of mountain bike tourism economic impacts and associated knowledge, the prevalence of such studies highlights the rise in mountain bike tourism and related strategies generally. Our analysis suggests that the extant academic and practitioner literature addressing mountain bike tourism economic impacts consists of disparate studies constituting a disjointed body of knowledge around mountain bike tourism. Consequently, there is a lack of coherent knowledge which community advocates may draw upon to convince policy makers that investment in mountain bike tourism initiatives represents a prudent use of public funds likely to generate positive economic impacts for host communities (Crompton, 1995). We suggest that it is counterproductive for academic and practitioner researchers seeking to measure mountain bike tourism impacts to continually deploy bespoke data collection instruments. This approach is generating a fragmented global body of knowledge around mountain bike tourism impacts that is of limited use to community groups seeking to develop business cases for governmental financial assistance and other resources to develop mountain bike tourism. 
Existing studies have largely restricted their analysis of economic impacts attributable to mountain bike tourism to elementary and inconsistent measures of expenditure associated with lodging; food and beverage; shopping; recreation; rental vehicle expenditures; and/or aggregate expenditure. Future studies require a more consistent approach to measuring mountain bike tourism economic impacts underpinned by principles of economic impact measurement as advocated within the broader tourism economics literature (e.g., Crompton, Lee, and Shuster, 2001; Frechtling, 1994; Preuss, 2005; Stynes and White, 2006).

Crompton (1995) identified 'failure to define the area of interest accurately' (p. 24) as one of 11 widespread contributors to inaccurate economic impact analyses in the context of sports facilities and events. Therefore, there is a fundamental need to apply a consistent technical definition of a mountain bike tourist in order to isolate and thus accurately assess economic impacts specifically attributable to mountain bike tourism (Lamont, 2009). Notably, none of the studies reviewed ascertained respondents' main trip purpose, nor travel distance from home region to the destination, casting some doubt on the validity of visitor expenditure estimates. Future studies should ensure that local residents and tourists are unambiguously differentiated to exclude expenditure by local residents whose money is already circulating within a local economy (Crompton et al., 2001). There is also a need to ensure measure travel party size is measured to reduce erroneous data stemming from individual respondents paying for others and vice versa (Crompton et al., 2001). More rigorous economic impact data is vitally important in order to attract and justify expenditure of public funds on developing infrastructure to support mountain bike tourism.

It is important to note that the studies reviewed tapped only into a limited number of variables pertaining to mountain bike tourists' travel characteristics. Although 26 relevant variables were identified, other research and industry standardized measures that would contribute to an enhanced understanding of the mountain bike tourism market and improved 
validity and reliability of the published results have largely been omitted. Such variables include main trip purpose, visitor spending categories, and other behavioral/preferential measures (see Table 2). Other useful variables relating to mountain bike tourism travel characteristics that future studies may consider include mode of transport to the destination; whether the respondent brought their own bicycle or rented a bicycle at the destination; engagement with local cycling support services; travel group composition (e.g., friends and/or family); travel seasonality; and repeat visitation/travel history to the destination.

Further, Buning et al.'s (2019) study of US mountain bike tourists identified widespread heterogeneity in travel behavior and preferences across various demographic groups, particularly age categories. Such heterogeneity may have implications for understanding nuances in economic impacts stemming from mountain bike tourism. We therefore suggest that additional demographic variables be considered in future studies such as relationship status and number/age of dependent children living at home. Doing so would enable more detailed analysis of the travel behaviors and impacts of sub-segments of mountain bike tourists which may inform enhanced product development and marketing strategies (Buning et al., 2019). Future studies may also benefit from including variables and measures aligning with those adopted by national-level statistical agencies (e.g., United States Census Bureau; Australian Bureau of Statistics) and mountain bike industry organizations (e.g., International Mountain Bike Association) to facilitate comparison between different studies and also with data at national levels.

A variety of methods could also potentially be used in quantifying the tourism impact of mountain bike travel such as Input-Output and Computable General Equilibrium models or Cost-Benefit Analysis (e.g., Dwyer, Forsyth, and Dwyer, 2010). One such study employed the Travel Cost Method to estimate economic benefits to Moab, Utah from mountain biking and found a consumer surplus of around \$200 USD per trip (Fix and Loomis, 1997). Still, the 
focus of this review was on direct visitor expenditure that is often used in persuading policymakers to fund community requests for financial support. 


\section{References}

Beeton S (2010) Regional community entrepreneurship through tourism: The case of Victoria's rail trails. International Journal of Innovation and Regional Development 2(1/2): 128-148

Boozer BB and Self M (2012) An economic and impact analysis of the Coldwater Mountain Bike Trail. Report for the Calhoun County Community Development Corporation. July.

Buning RJ, Cole, Z and Lamont M (2019) A case study of the US mountain bike tourism market. Journal of Vacation Marketing. Epub ahead of print 12 April 2019. DOI: $10.1177 / 1356766719842321$

Chakraborty K and Keith JE (2000) Estimation the recreation demand and economic value of mountain biking in Moab, Utah: An application of count data model. Journal of Environmental Planning and Management 46(4): 461-469.

Courtney P (2018) 'Mountain biking brings thousands of trail-riding enthusiasts to northern Tasmanian town' ABC News, 27 April, https://www.abc.net.au/news/2018-0421/world-class-mountain-bike-trail-transforms-derby-from-ghost-tow/9677344

Crompton J L (1995) Economic impact analysis of sports facilities and events:

Eleven sources of misapplication. Journal of Sport Management 9(1): 14-35.

Crompton J, Lee S and Shuster, T (2001) A guide for undertaking economic impact studies: The Springfest example. Journal of Travel Research 40(1): 79-87.

Dean Runyan Associates (2013) The economic significance of bicycle travel in Oregon. Report for Travel Oregon. April.

Destination British Columbia (2013) BC Input-Output Model Report: Mountain Biking in Rossland and Golden. Report Tourism British Columbia Ministry of Jobs, Tourism, and Skills Training. May. 
Dwyer L, Forsyth P and Dwyer W (2010). Tourism economics and policy. Bristol, UK: Channel View Publications.

Fix P and Loomis J (1997) The economic benefits of mountain biking at one of its meccas: an application of the travel cost method to mountain biking in Moab, Utah. Journal of Leisure Research 29(3): 342-352.

Frechtling D (1994) Assessing the economic impacts of travel and tourism - Introduction to travel economic impact estimation. In Ritchie JRB and Goeldner C (eds.) Travel, Tourism and Hospitality Research: A Handbook for Managers and Researchers $\left(2^{\text {nd }}\right.$ ed., Chapter 31). New York: John Wiley and Sons.

Freeman R and Thomlinson E (2014) Mountain bike tourism and community development in British Columbia: critical success factors for the future. Tourism Review International 18(1-2): 9-22.

Hodur N and Leistritz F (2006) Estimating the economic impact of event tourism. Journal of Convention \& Event Tourism 8(4): 63-79.

Hudson I (2001) The use and misuse of economic impact analysis. Journal of Sport \& Social Issues 25(1): 20-39.

Jenkins J (2000) The dynamics of regional tourism organisations in New South Wales, Australia: History, structures and operations. Current Issues in Tourism 3 (3): 175203

Kelly C (2014) Fat Tire Flyer: Repack and the Birth of Mountain Biking. Boulder: VeloPress Lamont M (2009) Reinventing the wheel: A definitional discussion of bicycle tourism. Journal of Sport \& Tourism 14(1): 5-23.

Lamont M and Jenkins J (2013) Segmentation of cycling event participants: A two stepcluster method utilizing recreation specialization. Event Management 17: 391-407. 
Lamont M, Kennelly M and Wilson E (2012) Competing priorities as constraints in event travel careers. Tourism Management 33: 1068-1079.

Moher D, Liberati A, Tetzlaff J et al. (2009) preferred reporting items for systematic reviews and meta-analyses: The PRISMA Statement. PLoS Medicine 6(7): 1-6.

Moran D, Tresidder E and McVittie, A (2006) Estimating the recreational value of mountain biking sites in Scotland using count data models. Tourism Economics 12(1): 123-135.

Moscardo G (2005) Peripheral tourism development: Challenges, issues and success factors. Tourism Recreation Research 30(1): 27-43.

Moularde J and Weaver A (2016) Serious about leisure, serious about destinations: Mountain bikers and destination attractiveness. Journal of Sport \& Tourism 20(3-4): 285-303.

Preez MD and Lee DE (2016) The economic value of the Trans Baviaans mountain biking event in the Baviaanskloof Mega-Reserve, Eastern Cape, South Africa: A travel cost analysis using count data models. Journal of Outdoor Recreation and Tourism 15: 4754.

Preuss H (2005) The economic impact of visitors at major multi-sport events. European Sport Management Quarterly 5(3): 281-301.

Reis A., Lovelock, B and Jellum, C. (2014) Linking tourism products to enhance cycle tourism: The case of the Taieri Gorge Railway and the Otago Central Rail Trail, New Zealand. Tourism Review International 18(1/2): 57-69.

Stynes DJ and White EM (2006) Reflections on measuring recreation and travel spending. Journal of Travel Research 45(1): 8-16.

Sumathi NR and Berard DA (1997) Mountain bicycling in Wisconsin surveyed and analyzed. Report, University of Wisconsin, USA. 
Tabor M (2014) Economic impact of mountain biking on Mount Macpherson Executive Summary. Report for Tourism Revelstoke. October.

Weed M (2005) Research synthesis in sport management: Dealing with "chaos in the brickyard. European Sport Management Quarterly 5(1): 77-90.

Western Canada Mountain Bike Tourism Association (2006) Sea to Sky Mountain Biking Economic Impact Study Overall Results.

Western Canada Mountain Bike Tourism Association (2017) Mountain Biking Economic Impact Study North shore. 
Table 1: Variables included in reviewed mountain bike tourism economic impact studies $(N=33)$

\begin{tabular}{|c|c|c|c|}
\hline Grouped Variable Categories & Variables Measured in Existing Studies & $\mathbf{N}$ & $\%$ \\
\hline \multirow{6}{*}{ Individual demographic characteristics } & Age & 23 & 69.7 \\
\hline & Gender & 22 & 66.7 \\
\hline & Income & 13 & 39.39 \\
\hline & Educational attainment & 5 & 15.15 \\
\hline & Employment status & 2 & 6.1 \\
\hline & Household composition (inc. mean household size) & 2 & 6.1 \\
\hline \multirow{2}{*}{ Individual mountain biking characteristics } & Mountain biking skill level & 8 & 24.2 \\
\hline & Number of days spent mountain biking each year & 4 & 12.12 \\
\hline Destination choice & Destination choice influencers & 4 & 12.12 \\
\hline \multirow[t]{9}{*}{ Mountain bike tourism travel characteristics } & Travel group size & 20 & 60.6 \\
\hline & Trip length (nights or days) & 15 & 45.5 \\
\hline & Types of lodging utilized & 9 & 27.3 \\
\hline & Motivation & 3 & 9.09 \\
\hline & Number of trips taken each year & 5 & 15.15 \\
\hline & Time spent mountain biking (hours per day) & 1 & 3.0 \\
\hline & Types of mountain biking (e.g., cross country, downhill) & 1 & 3.0 \\
\hline & Satisfaction & 2 & 6.1 \\
\hline & Sources of information & 2 & 6.1 \\
\hline \multirow[t]{8}{*}{ Mountain bike tourism expenditure } & Total expenditure & 30 & 90.91 \\
\hline & Lodging & 22 & 66.7 \\
\hline & Food and beverage (restaurants and groceries) & 22 & 66.7 \\
\hline & Shopping (general shopping and bike related) & 21 & 63.6 \\
\hline & Recreation & 18 & 54.6 \\
\hline & Daily expenditure per person & 16 & 48.5 \\
\hline & Rental vehicle & 15 & 45.5 \\
\hline & Daily expenditure & 7 & 21.2 \\
\hline
\end{tabular}


Table 2: Suggested Measurement of Variables in Mountain Bike Impact Research

\begin{tabular}{|c|c|c|c|}
\hline $\begin{array}{l}\text { Variable } \\
\text { Categories }\end{array}$ & $\begin{array}{c}\text { Existing Variables to be } \\
\text { Retained }\end{array}$ & Suggested Additional Variables & Rationale \\
\hline $\begin{array}{l}\text { Mountain bike } \\
\text { tourism } \\
\text { expenditure }\end{array}$ & $\begin{array}{l}\text { Lodging } \\
\text { Food and beverage (restaurants } \\
\text { and groceries) } \\
\text { Recreation other than cycling } \\
\text { Daily expenditure } \\
\text { Daily expenditure per person } \\
\text { Total expenditure }\end{array}$ & $\begin{array}{l}\text { Travel costs (including vehicle rental } \\
\text { costs; fuel for rental or own vehicle) } \\
\text { Cycling -related expenditure (e.g., } \\
\text { spare parts) } \\
\text { Retail (excluding cycling-related } \\
\text { expenditure) } \\
\text { Incidental expenditure (e.g., first- } \\
\text { aid/pharmacy) } \\
\text { Event registration fees } \\
\text { Number of persons covered by } \\
\text { expenditure responses }\end{array}$ & $\begin{array}{l}\text { Future studies should employ a broader } \\
\text { range of expenditure variables than } \\
\text { existing studies have, to improve mutual } \\
\text { exclusivity between expenditure } \\
\text { categories. } \\
\text { Studies should better distinguish } \\
\text { cycling-related expenditure from } \\
\text { general expenditure in order to more } \\
\text { accurately estimate the economic value } \\
\text { of the cycling industry. } \\
\text { Expenditure measures should also } \\
\text { explicitly differentiate expenditure } \\
\text { between that made in the home region } \\
\text { and destination region to more } \\
\text { accurately capture new money injected } \\
\text { into a host destination economy (i.e., } \\
\text { Crompton, 1995). }\end{array}$ \\
\hline $\begin{array}{l}\text { Mountain bike } \\
\text { tourism travel } \\
\text { characteristics }\end{array}$ & $\begin{array}{l}\text { Travel group size } \\
\text { Trip length (number of } \\
\text { nights/days) } \\
\text { Types of lodging utilized }\end{array}$ & $\begin{array}{l}\text { Mode of transport to mountain biking } \\
\text { destination } \\
\text { Mountain biking tourism travel history } \\
\text { Utilized own bike or rental bike }\end{array}$ & $\begin{array}{l}\text { A more comprehensive range of } \\
\text { mountain bike tourism travel } \\
\text { characteristic measures are needed to } \\
\text { facilitate (i) more rigorous segmentation }\end{array}$ \\
\hline
\end{tabular}




Number of trips taken each year
Time spent mountain biking
(hours per day)
Types of mountain biking
participated in (e.g., cross
country, downhill)

Number of trips taken each year

Engagement with local cycling support services (e.g., guides, bike shops, mountain biking clubs)

Participation in other activities at destination besides mountain biking Trip purpose (e.g., mountain biking main purpose versus secondary/incidental participation) Travel party composition (e.g., friends and/or family)

Travel dates (seasonality)

Event/non-event travel

Lodging - which town/suburb?

Repeat visitation/travel history to destination

Consider revisiting the area for trips other than mountain biking? of the market; (ii) more nuanced understanding of mountain bike tourism travel behavior; and (iii) greater understanding of engagement with and demand for supply-side services (e.g., Buning, Cole, and Lamont, 2019; Freeman and Thomlinson, 2014).

Additional measures are required to understand the influence of factors such as travel party composition, seasonality, event participation, and repeat visitation on mountain bike tourism economic impacts.

Determination of core trip purpose is needed to ensure expenditure is exclusively attributable to mountain bike tourism (e.g., Crompton, 1995; Lamont, 2009).

Demographic variables employed in existing studies provide only limited insights into individual participants' demographic characteristics that may shape or constrain participation in mountain biking tourism (e.g., influence of having young dependent children

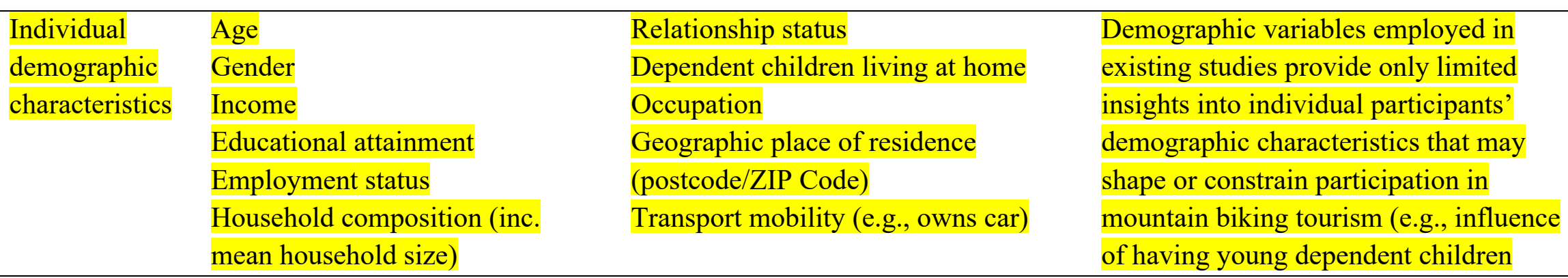


living at home) (e.g., Lamont, Kennelly, and Wilson, 2012).

Determining geographic place of residence helps to ensure expenditure by local residents is excluded from economic impact analyses. (e.g., Crompton, 1995; Dwyer, Forsyth, and Dwyer, 2010)

Use of measures and response categories that align with national statistical agency measures can facilitate comparison with national-level data.

Individual Number of days spent mountain
mountain biking each year

biking

characteristics
Theory-based mountain biking specialization

Skill based on trail difficulty

standards.

Mountain bike disciplines

Event participation patterns

Group composition when mountain

biking around home region

Club/group membership

Motivation for participating in mountain biking
Variables employed in existing

literature are largely atheoretical and prevent nuanced segmentation of the mountain bike tourism market.

Theory-driven measures of centrality, involvement, and/or recreation specialization may provide enhanced insights into nuances among groups of mountain bike tourism participants. Such insights may be used to tailor tourism product design and marketing according to the needs of particular 
groups (e.g., Lamont and Jenkins, 2013).

Adopting more rigorous measures of individual mountain biking characteristics may also aid enhanced understanding of the economic value of various groups.

\begin{tabular}{|c|c|c|c|}
\hline $\begin{array}{l}\text { Destination } \\
\text { choice }\end{array}$ & Destination choice influencers & Destination information sources & $\begin{array}{l}\text { Enhanced understanding of where } \\
\text { mountain bike tourists obtain } \\
\text { information regarding prospective } \\
\text { destinations may enhance the ability of } \\
\text { tourism marketers to reach and target } \\
\text { particular groups of mountain biking } \\
\text { tourists. }\end{array}$ \\
\hline
\end{tabular}

